\title{
Stain Removal from a Silicone Maxillofacial Elastomer
}

\author{
R. YU, A. KORAN, C.N. RAPTIS, and R.G. CRAIG
}

The University of Michigan, School of Dentistry, Ann Arbor, Michigan 48109

In this study, environmental stains were removed from maxillofacial elastomers by solvent extraction. Silastic 44210, an RTV silicone with proven color and physical property stability, was stained with lipstick, disclosing solution, and methylene blue. These stains were then removed by solvent extraction with each of four chemically dissimilar solvents, namely: toluene, benzene, 1,1,1-trichloroethane, and n-hexane. An additional series of samples was prepared with 11 maxillofacial pigments, not for staining, but for evaluation of pigment stability. Results obtained from spectrophotometric measurements before and after solvent extraction demonstrated the effectiveness of solvent extraction in removing stains, while there was little or no change in the color of the pigments or the base elastomer.

\section{J Dent Res 60(10):1754-1758, October 1981}

\section{Introduction.}

In earlier studies dealing with the physical properties and color stability of various maxillofacial elastomers under conditions of accelerated aging, results indicated that the service life of a prosthesis can be extended by selection of base materials with proven color and physical property stability, and color-stable pigments. ${ }^{1-3}$ It has also been demonstrated that staining is the most likely cause of discoloration of maxillofacial prostheses $^{4}$ and may be responsible for frequent replacement, which places a financial burden on the patient and taxes the facilities where the prostheses are made.

According to the theory of rubber elasticity, ${ }^{5}$ when a polymer network is placed in contact with an excess of a thermodynamically good solvent, it will continuously absorb solvent until the increase in elasticfree energy (due to the three-dimensional, isotropic deformation of the network) is offset by the decrease in free energy (due to mixing of polymer chains and solvent),

Received for publication November 29, 1979

Accepted for publication March 20, 1981

This study was supported by U.S. Public Health Service Grant DE-04136 from the National Institute of Dental Research, National Institutes of Health, Bethesda, MD 20205. and swelling equilibrium is established. Subsequent de-swelling should not alter the original stress-strain behavior of the elastomer. ${ }^{6,7}$ At swelling equilibrium, diffusion of soluble stains from the swollen maxillofacial rubber into the solvent should take place because of the concentration gradient of the stain in the nubber and the solvent.

The purpose of the present study was to establish a cleaning technique to remove environmental stains by swelling and solvent extraction, thereby restoring the original appearance and extending the service life of the prostheses. A maxillofacial elastomer was stained with several strong stains, and these stains were subsequently removed by solvent extraction. Color changes were measured with a reflectance spectrophotometer, and the efficiency of stain removal and the effects of the solvents on the base elastomer and maxillofacial pigments were evaluated.

\section{Materials and methods.}

Silastic $44210^{*}$ was chosen as the base elastomer for the present study because: 1) It is an elastomer with proven color and physical property stability; $;^{1}$ ) it can be easily pigmented and fabricated into a prosthesis; and 3) it has the characteristic of forming a three-dimensional cross-linked network - a quality required for successful swelling and extraction by solvents. Silastic $44210^{*}$ is a two-component, room temperature-cured silicone, and the pre-polymer is a moderately viscous fluid. For all comparisons, five samples $(6 \times 4 \times 0.35 \mathrm{~cm})$ were prepared according to the manufacturers' instructions. Prior to staining, these samples were tested for color stability of the base elastomer before and after solvent extraction by reflectance spectrophotometry.

Three common staining agents were used to stain the base material. These were lipstick, disclosing solution, and methylene

\footnotetext{
*Dow Corning Corporation, Midland, MI
} 
blue. The lipstick used was a deep red shade, ${ }^{\dagger}$ and this stain was applied to each sample by alternating horizontal and vertical applications until a uniform covering on the surface was achieved. After standing at room temperature for $24 \mathrm{~h}$ to allow stain penetration, the samples were wiped with a dry cloth to remove the surface stain, cleaned with a cleansing skin cream, $\ddagger$ washed with soap, and then dried prior to spectrophotometric measurements. The disclosing solution was a product specifically used for disclosing dental plaque and was prepared from $45 \mathrm{~g}$ Bismark Brown, $1800 \mathrm{cc}$ glycerine, $15 \mathrm{cc}$ of $95 \%$ ethyl alcohol, and $1 \mathrm{cc}$ of oil of anise flavoring. The staining solution was further diluted by one part of the disclosing solution to three parts distilled water. The methylene blue product $\$$ used was a biological stain, and, for our purposes, it was dissolved in distilled water to form a $0.1 \%$ by weight solution. Staining was accomplished with the solutions by sample immersion at room temperature for $24 \mathrm{~h}$ with constant solution agitation. The samples were cleaned and dried prior to color analysis to remove any surface stain as described in an earlier study. ${ }^{4}$ Four chemically dissimilar organic solvents were selected to test their potential for stain removal, and these were toluene, benzene, 1,1,1-trichloroethane, and n-hexane. ${ }^{8}$

The removal of stains was carried out by swelling the samples in each solvent for a period of two $d$ and with constant solvent stirring. The swollen samples were then deswollen by subsequent addition of methanol and eventually dried to constant weight under vacuum to remove all traces of solvents.

Four additional series of samples were pigmented with $0.2 \%$ by weight of commercially available maxillofacial pigments, \# not for staining, but for pigment stability analysis after solvent extraction. The pigments were white (W), yellow (Y), dark

$\dagger$ Big Apple, \#03301, Cover Girl Moisturized Shiny Lipsticks, Noxell Corporation, Baltimore, MD

$\ddagger$ Noxema greaseless skin cream, Noxell Corporation, Baltimore, MD

$\S$ Certified for use by the Biological Stain Commission, University of Rochester Medical Center, Rochester, NY

\#Artskin Products, Inc., Norfolk, VA 23502 buff (Dk Bf), medium brown (MB), light brown (Lt B), red brown (RB), black (B1), red $(R)$, blue $(\mathrm{Bu})$, light orange (Lt $\mathrm{O})$, and yellow orange (YO).

The color of the stained samples was measured before and after staining and after solvent extraction using a double-beam reflectance spectrophotometer with an integrating sphere. The color of the pigmented samples was measured before and after solvent extraction. For color analysis, reflectance curves were obtained for all samples backed by a barium sulfate reference standard, and luminous reflectance (LR), dominant wavelength (DW), and excitation purity (EP) were calculated from these curves for all conditions relative to the C.I.E. $\phi$ Chromaticity Diagram 1931 and Source A. ${ }^{9,10}$ LR is a measure of lightness or darkness with values ranging from 0 for black to 100 for white. DW is the actual color as perceived by a standard observer and ranges from 400 to $700 \mathrm{~nm}$, which is the visible spectrum. EP is a measure of color saturation. It varies from 0 for absence of color to 1.0 for complete color saturation. The means and standard deviations of these color parameters were calculated from the results of each experimental condition and were then statistically compared by analysis of variance ${ }^{11}$ and Scheffe intervals ${ }^{12}$ at a $95 \%$ level of confidence.

\section{Results.}

Results obtained for the stain removal study and color analysis of pigmented samples were similar for all solvents studied. For brevity, the results of the color analysis are presented only for n-hexane extraction, since the results were almost identical for the four solvents. The means and standard deviations listed in Tables 1 through 4 were calculated from the spectrophotometric measurements of five samples for each experimental condition. Tables 1,2 , and 3 describe the LR, DW, and EP of the base elastomer before and after extraction, stained with each staining agent, and cleaned by solvent extraction. The Scheffe intervals are listed in each Table. As seen in Table 1, the LR, DW, and EP of the elastomer did

I ACTA CIII UV-visible spectrophotometer, Beckman Instruments, Inc., Irvine, CA 92664

IInternational Commission on Illumination 
TABLE 1

RESULTS OF LIPSTICK STAIN REMOVAL FROM

S 44210 BY $n$-HEXANE EXTRACTION

\begin{tabular}{l|c|c|c|c|c}
\hline Condition & $\begin{array}{c}\text { Before } \\
\text { Extraction }\end{array}$ & $\begin{array}{c}\text { After } \\
\text { Extraction }\end{array}$ & $\begin{array}{c}\text { Lipstick } \\
\text { Stained }\end{array}$ & Cleaned & $\begin{array}{c}\text { Scheffe } \\
\text { Interval }\end{array}$ \\
\hline $\begin{array}{l}\text { Luminous } \\
\text { Reflectance }\end{array}$ & $\begin{array}{c}84.3 \\
(1.2)^{*}\end{array}$ & $\begin{array}{c}84.3 \\
(1.2)\end{array}$ & $\frac{77.1}{(0.8)}$ & $\begin{array}{c}83.6 \\
(1.0)\end{array}$ & 1.8 \\
\hline $\begin{array}{l}\text { Dominant } \\
\text { Wavelength }\end{array}$ & $\begin{array}{c}584.5 \\
(0.2)\end{array}$ & $\begin{array}{c}584.5 \\
(0.3)\end{array}$ & $\frac{613.9}{(2.5)}$ & $\begin{array}{c}584.7 \\
(0.2)\end{array}$ & 2.3 \\
$\begin{array}{l}\text { Excitation } \\
\text { Purity }\end{array}$ & $\begin{array}{c}0.078 \\
(0.002)\end{array}$ & $\begin{array}{c}0.078 \\
(0.002)\end{array}$ & $\frac{0.063}{(0.001)}$ & $\begin{array}{c}0.076 \\
(0.002)\end{array}$ & 0.004 \\
\hline
\end{tabular}

*Standard deviations in parentheses.

Underlines $=$ statistical difference at $95 \%$ level of confidence.

TABLE 2

RESULTS OF DISCLOSING SOLUTION STAIN REMOVAL FROM S 44210 BY n-HEXANE EXTRACTION

\begin{tabular}{l|c|c|c|c|c}
\hline Condition & $\begin{array}{c}\text { Before } \\
\text { Extraction }\end{array}$ & $\begin{array}{c}\text { After } \\
\text { Extraction }\end{array}$ & $\begin{array}{c}\text { Disclosing } \\
\text { Solution } \\
\text { Stained }\end{array}$ & Cleaned & $\begin{array}{c}\text { Scheffe } \\
\text { Interval }\end{array}$ \\
\hline $\begin{array}{l}\text { Luminous } \\
\text { Reflectance }\end{array}$ & $\begin{array}{c}83.9 \\
(0.3)^{*}\end{array}$ & $\begin{array}{c}83.8 \\
(0.2)\end{array}$ & $\frac{77.7}{(0.7)}$ & $\begin{array}{c}84.4 \\
(0.4)\end{array}$ & 0.8 \\
\hline $\begin{array}{l}\text { Dominant } \\
\text { Wavelength }\end{array}$ & $\begin{array}{r}584.6 \\
(0.2)\end{array}$ & $\begin{array}{c}584.4 \\
(0.2)\end{array}$ & $\frac{584.4}{(0.1)}$ & $\begin{array}{c}584.5 \\
(0.2)\end{array}$ & 0.4 \\
\hline $\begin{array}{l}\text { Excitation } \\
\text { Purity }\end{array}$ & $\begin{array}{r}0.078 \\
(0.003)\end{array}$ & $\begin{array}{c}0.079 \\
(0.003)\end{array}$ & $\frac{0.596}{(0.023)}$ & $\begin{array}{c}0.081 \\
(0.002)\end{array}$ & 0.023 \\
\hline
\end{tabular}

*Standard deviations in parentheses.

Underlines $=$ statistical difference at $95 \%$ level of confidence.

TABLE 3

RESULTS OF METHYLENE BLUE STAIN REMOVAL FROM S 44210 BY n-HEXANE EXTRACTION

\begin{tabular}{l|c|c|c|c|c}
\hline Condition & $\begin{array}{c}\text { Before } \\
\text { Extraction }\end{array}$ & $\begin{array}{c}\text { After } \\
\text { Extraction }\end{array}$ & $\begin{array}{c}\text { Methylene } \\
\text { Blue } \\
\text { Stained }\end{array}$ & Cleaned & $\begin{array}{c}\text { Scheffe } \\
\text { Interval }\end{array}$ \\
$\begin{array}{l}\text { Luminous } \\
\text { Reflectance }\end{array}$ & $\begin{array}{c}85.0 \\
(0.3)^{*}\end{array}$ & $\begin{array}{c}85.0 \\
(0.5)\end{array}$ & $\frac{78.6}{(1.4)}$ & $\begin{array}{c}85.5 \\
(0.4)\end{array}$ & 1.5 \\
\hline $\begin{array}{l}\text { Dominant } \\
\text { Wavelength }\end{array}$ & $\begin{array}{c}584.2 \\
(0.1)\end{array}$ & $\begin{array}{c}584.2 \\
(0.1)\end{array}$ & $\frac{581.2}{(1.0)}$ & $\begin{array}{c}584.2 \\
(0.2)\end{array}$ & 1.0 \\
\hline $\begin{array}{l}\text { Excitation } \\
\text { Purity }\end{array}$ & $\begin{array}{r}0.076 \\
(0.002)\end{array}$ & $\begin{array}{c}0.077 \\
(0.002)\end{array}$ & $\frac{0.069}{(0.001)}$ & $\begin{array}{c}0.079 \\
(0.002)\end{array}$ & 0.003 \\
\hline
\end{tabular}

*Standard deviations in parentheses.

Underlines = statistical difference at $95 \%$ level of confidence. 
not change before and after solvent extraction prior to staining. This demonstrates color stability of the base elastomer when exposed to solvent extraction with $\mathrm{n}$-hexane. The values of $L R, D W$, and EP for all samples changed significantly after staining with lipstick. The original values for $L R$, DW, and EP were restored after $n$-hexane extraction, demonstrating the great effectiveness of the solvent in removing the lipstick stain.

Table 2 shows the results of solvent extraction on the disclosing solution stain. Prior to staining, the values of LR, DW, and EP of the base elastomer before and after each solvent extraction did not change. The samples became darker after staining as indicated by the decrease in LR from 83.8 $(0.2)$ to $77.1(0.7)$. The value for $\mathrm{DW}$ at $584.4(0.2)$ remained essentially unchanged with the disclosing solution stain. However, the EP increased from $0.079(0.003)$ to $0.596(0.023)$, indicating a large increase in color saturation. The effectiveness of stain removal by solvent extraction was once again demonstrated. The values for $L R$, DW, and EP were the same as those prior to staining.

In Table 3 , results for the methylene blue stain are similar to those for the two previous stains. Solvent extraction again did not affect the color stability of the base elastomer. The methylene blue stain changed the LR, DW, and EP of the samples; however, after solvent extraction the original values of LR, DW, and EP were restored.

The results obtained for pigment stability analysis are presented in Table 4 along with the respective Scheffe intervals. The effect of solvent extraction with $n$-hexane on the LR of the 11 maxillofacial pigments indicates no significant change in LR for any of the pigments after solvent extraction. These results were important since solvent extraction would be of little or no value if the pigments used to color a prosthesis were extracted along with the stains. The DW of the pigmented samples before and after solvent extraction also exhibited no change for any of the 11 pigments. Ten of the 11 pigments demonstrated no change in EP. One pigment, white, did change in EP; however, this change was very small at 0.029 . The values for $L R, D W$, and EP before and after $n$-hexane extraction were similar to those for the other solvents. Only the white pigment changed in color with EP, increasing from $0.026(0.002)$ before extraction to $0.055(0.004)$ after solvent extraction.

\section{Discussion.}

The method of staining was identical to that used in a previous study. ${ }^{4}$ Since there are no standardized tests for analysis of stain removal, the experimental conditions of concentration of stain, temperature, and length of exposure were chosen as arbitrary limits based upon pilot studies using those stains. Though they do not reflect standardized test methods, they are reasonable for future comparisons for other elastomers and stains.

Prior to staining, no statistical changes in the LR, DW, and EP of the unpigmented samples were observed before and after immersion in each of the solvents, thus eliminating the possibility of color changes in the base material when in contact with the solvents. After staining, lipstick, disclosing solution, and methylene blue produced significant changes in LR and EP. Lipstick and methylene blue changed the DW of the base elastomer, while disclosing solution did not. Though the DW of the samples remained unaltered by the disclosing solution stain, the large increase in EP made this stain highly visible. For each experimental condition, no significant changes in color were seen before staining and after stain removal by solvent extraction, indicating the total effectiveness of all solvents in removing the stains. Since the results were essentially identical for all four solvents, the data for n-hexane were used to represent the group of solvents.

The color stability of the pigments after solvent extraction is very important, since solvent extraction would be of little or no value if the pigments used to color a prosthesis were extracted along with the stains. Ten of the 11 pigments demonstrated no change in color, while one pigment, white, did change slightly in EP after solvent extraction. It must be emphasized that, although the increase in EP of 0.029 was statistically significant, this change in EP is small and might not be observed visually. This does emphasize, however, the importance of testing the color stability of pigments that will be exposed to solvent ex- 
TABLE 4

COLOR STABILITY OF PIGMENTED SAMPLES BEFORE AND AFTER n-HEXANE EXTRACTION

\begin{tabular}{|c|c|c|c|c|c|c|c|c|c|}
\hline \multirow[b]{2}{*}{ Pigment } & \multicolumn{2}{|c|}{ Luminous Reflectance } & \multirow{2}{*}{$\begin{array}{l}\text { Scheffe } \\
\text { Int. }\end{array}$} & \multicolumn{2}{|c|}{ Dominant Wavelength } & \multirow{2}{*}{$\begin{array}{l}\text { Scheffe } \\
\text { Int. }\end{array}$} & \multicolumn{2}{|c|}{ Excitation Purity } & \multirow{2}{*}{$\begin{array}{c}\text { Scheffe } \\
\text { Int. }\end{array}$} \\
\hline & Before & After & & Before & After & & Before & After & \\
\hline 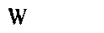 & $87.7(1.3)^{*}$ & $85.2(1.2)$ & 1.8 & $577.8(1.9$ & 5 & 33 & $26(0.002)$ & 0.055 & 0.004 \\
\hline $\mathrm{Y}$ & $74.8(1.5)$ & & & & & 0 & 1) & 93) & 0.003 \\
\hline $\mathrm{Dk} \mathrm{Bf}$ & $44.4(0.7)$ & $44.0(0.5)$ & 0. & $(0.1)$ & $591.8(0.1)$ & 0.1 & 0.7778 & $.002)$ & 0.005 \\
\hline MB & $9.8(0.3)$ & $9.7(0.2)$ & 0.3 & $604.1(0.2)$ & $604.2(0.1)$ & 0.2 & $0.585(0.004)$ & $0.585(0.006)$ & 0.011 \\
\hline Lt B & $25.9(0.9)$ & $25.4(0.7)$ & 1.2 & & $6(0.4)$ & 0.6 & $9(0.009)$ & $0.782(0.007)$ & 0.012 \\
\hline RB & 10. & 10.2 & 0.5 & & & & 66) & $0.525(0.005)$ & 0.007 \\
\hline $\mathrm{Bl}$ & 1) & & & & & 0 & 0.0 & & 0.001 \\
\hline $\mathbf{R}$ & $14.2(0.1)$ & $14.2(0.2)$ & 0 . & $0.1)$ & $626.0(0.1)$ & 0.1 & $0.786(0.004)$ & 0.784 & 0.006 \\
\hline $\mathrm{Bu}$ & $9.5(0.4)$ & $9.4(0.3)$ & 0.5 & $480.0(0.2)$ & $480.2(0.1)$ & 0.2 & $0.496(0.009)$ & $0.495(0.007)$ & 0.012 \\
\hline Lt $\mathrm{O}$ & $45.8(0.7)$ & $45.9(0.5)$ & 0.9 & $597.3(0.1)$ & $597.5(0.1)$ & 0.2 & $0.917(0.002)$ & $0.917(0.003)$ & 0.004 \\
\hline YO & $71.5(0.4)$ & $71.2(0.4)$ & 0.6 & $585.6(0.0)$ & $585.7(0.1)$ & 0.1 & $0.913(0.002)$ & $0.912(0.002)$ & 0.003 \\
\hline
\end{tabular}

*Standard deviations in parentheses.

Underlines $=$ statistical difference at $95 \%$ level of confidence.

traction, since pigments which are altered by solvents can be replaced with the more color-stable pigment.

During the extraction of stains, the solvent was not only being absorbed into the network, but it also interacted with the stain that had penetrated into the elastomer matrix. The action of solvent absorption represents only a pure physical mixing of network chains with solvent molecules, whereas the interaction between the solvents and the stains resulted in stain dissolution. Due to the concentration gradient, these dissolved stains were transported out from the body of the elastomer by diffusion at the swelling state. For the pigmented samples, pigment particles were generally insoluble in the solvents and were permanently entrapped in the three-dimensional cross-linked network of the base elastomer even when swelling equilibrium was reached.

\section{Conclusions.}

The results obtained from the present study demonstrated that solvent extraction was effective in removing stains from Silastic 44210 and had little or no effect upon the color of the pigments used. These results are encouraging and should have clinical application.

\section{REFERENCES}

1. YU, R.; KORAN, A.; and CRAIG, R.G.: Physical Properties of Elastomers for Maxillo- facial Appliances under Accelerated Aging, $J$ Dent Res 59:1141, 1980.

2. CRAIG, R.G.; KORAN, A.; YU, R.; and SPENCER, J.: Color Stability of Elastomers for Maxillofacial Appliances, $J$ Dent Res 57: 866-871, 1978.

3. KORAN, A.; YU, R.; POWERS, J.M.; and CRAIG, R.G.: Color Stability of a Pigmented Elastomer for Maxillofacial Appliances, $J$ Dent Res 58:1450, 1979.

4. KORAN, A.; POWERS, J.M.; LEPEAK, P.J.; and CRAIG, R.G.: Stain Resistance of Maxillofacial Materials, $J$ Dent Res 58:1455, 1979.

5. FLORY, P.J.: Statistical Mechanics of Swelling of Network Structures, $J$ Chem Phys 18: 108-112, 1950.

6. YU, C.U.: Experimental Studies of Rubberlike Elasticity, University of Michigan, Chemistry Department, 1974. Thesis.

7. YU, C.U. and MARK, J.E.: Evaluation of the Theories of Rubberlike Elasticity using Swollen Networks Crosslinked at Different Degrees of Dilution, Rubber Chem and Tech 48:186, 1975.

8. BRANDRUP, J. and IMMERGUT, E.H.: Polymer Handbook, New York: Wiley Interscience Publishers, 1966, $230 \mathrm{p}$.

9. WYSZECKI, G. and STILES, W.S.: Color Science, New York: Wiley and Sons, Inc., $1967,628 \mathrm{p}$.

10. BILLMEYER, F.R. and SALTZMAN, M.: Principles of Color Technology, New York: Wiley and Sons, Inc., 1966, 23 p.

11. DALBY, J.: BMD8V - Analysis of Variance, Ann Arbor: Statistical Research Laboratory, $1968,4 \mathrm{p}$.

12. GUENTHER, W.C.: Analysis of Variance, Englewood Cliffs, NJ: Prentice-Hall, 1964, $199 \mathrm{p}$. 